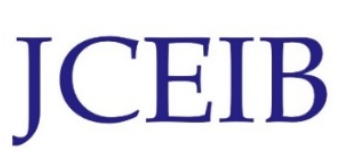

Journal Chemical Engineering and Industrial Biotechnology (JCEIB)

Open Access

Volume 2 pp. 59-67; September 2017

(C)Universiti Malaysia Pahang Publisher

DOI: https://doi.org/10.15282/JCEIB-V2-03.29/9/2017/2.2

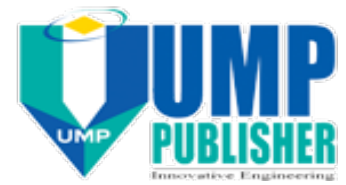

\title{
THE EFFECTS OF MICROWAVE HEATING ON THE EXTRACTION YIELD AND ELEMENTAL COMPOSITION OF BLACK AND WHITE PEPPER (Piper nigrum) EXTRACTS
}

\author{
Olusegun Abayomi Olalere, Nour Hamid Abdurahman*, Rosli bin Mohd. Yunus, \\ Oluwaseun Ruth Alara \\ Faculty of Chemical and Natural Resources Engineering, Universiti Malaysia Pahang, Lebihraya Tun \\ Razak, 26300 Gambang, Kuantan, Pahang, Malaysia \\ * Corresponding author: E-mail: nour2000_99@yahoo.com \\ Tel.: +60129134403
}

\begin{abstract}
Black and white peppers are functional crops, used in food industries as spice and in traditional medicine, for the treatment of many degenerative diseases. This study investigated the influence of microwave heating on the extraction yield, energy absorption and dietary elemental composition of oleoresin extracts from black and white pepper. Under the largest donating rule, the maximum extract yield obtained was 48.22 $\mathrm{mg} / \mathrm{g}$ from black pepper and $79.02 \mathrm{mg} / \mathrm{g}$ from white pepper microwave. The study therefore elucidated the energy absorption capacities in microwave heating and its resultant effects on extraction yield. This clearly showed the potentials of microwave technology in obtaining high quality extracts with properly controlled parameters.
\end{abstract}

Keywords: Black and white pepper; Energy dispersive x-ray (EDX); Largest donating rule; Microwave reflux extraction.

\subsection{INTRODUCTION}

Fresh black and white pepper are flowering vine of Piperaceae family found mostly in tropical countries such as India, Malaysia, Brazil and Thailand (Abdurahman \& Olalere, 2016; Friedman et al., 2008). The major difference between black and white pepper is in relation to their maturation time and method of processing (Olalere et al., 2017). The fruits of white pepper is allowed to fully matured before being plucked (Singh et al., 2013). It is then soaked inside water for some time and the fresh outer layer allowed to deteriorate before being scratched off to form a dried creamy coloured white peppercorns (Meghwal and Tk, 2012). However, black pepper is produce by force-drying an unripe flowering green fruits to form a deep brown wrinkled peppercorns. The extracts from black and white pepper have shown remarkable usefulness in elongating the shelf life of some dairy products, most especially in the preservation of food. Research has shown the effects of oleoresin extracts in the stimulation of gastro-intestinal walls which explains its medicinal benefits in the prevention of constipation and indigestion (Madhu et al., 2009; Mehmood and Gilani, 2010; Buckle,1985). The oleoresin extracts contain substantial amount of antioxidants, associated with the presence of unsaturated amides. The bioactive compound in both peppers prevents chemical carcinogenesis through the activation of xenobiotic enzymes. Hence the dietary its intake could provide natural 
antioxidants in boosting body immunity and an eventual prevention of degenerative diseases. Mageed et al. (2011) made a comparison between the antioxidant activity of the spice oil extracted from white and black pepper.

The microwave reflux extraction is such method which combines the conventional heating and microwave technology to extracts bioactive components from plant origin. Due to the environmental effect and health issues, the use of green solvent such as water is of necessity (Raman \& Gaikar, 2002). Although microwave assisted hydrodistillation (MAHD) method had been previously used in extracting volatile oil (essential oil) from black and white pepper. This method is however not suitable when extracting fixed oil as it could result in superheating which denature the thermo labile components (Moraes et al., 2013; Olalere et al., 2017). This study therefore investigates the effects of microwave heating and some extraction parameters on oleoresin yield and absorbed microwave energy.

\section{Materials}

\subsection{METHODS AND MATERIALS}

The standard grade dried black and white pepper was purchased from Sarawak, Malaysia with an initial moisture content of 3-4. The dried samples were ground using a Grindomix grinder (GM-200 model, Germany). The powdered sample was thereafter sieved into five different particle sizes $(0.105 \mathrm{~mm}, 0.154 \mathrm{~mm}, 0.300 \mathrm{~mm}, 0.450 \mathrm{~mm}$ and $0.900 \mathrm{~mm})$ and kept in an air-tight plastic.

\section{Microwave Reflux Extraction}

The extraction process was carried out using the ETHOS-Milestone extractor (ATC-FO300 , N. America). $25 \mathrm{~g}$ of the powder sample was mixed with a known quantity of distilled water and thoroughly mixed using a magnetic stirrer. The mixture was then loaded into the microwave cavity and subjected to a rapid microwave heating using parameters obtained from the single factor experimental design. After extraction, the reactor was unloaded from the microwave cavity and concentrated with rotary evaporator (BUCHI, R-200 model, Germany). The concentrated extracts were collected, weighed and stored in a dark glass bottles for subsequent analysis. The percentage yield of the extract was calculated on dried basis.

\section{Experimental Design}

Single factor experimental design was used to investigate the effect of extraction parameters on the amount of fixed oil yield and energy absorbed. This was achieved by keeping all other parameters constant while varying a single parameter from a series of iterative batch experiments $(\mathrm{Qu}$ and $\mathrm{Wu}, 2005)$. For each variation, the maximum response was selected and the overall extraction condition determined. The merit of using this design was to carry out a preliminary investigation and a continuous monitoring of happenings in each test runs (Olalere et al., 2017). The extractions parameters considered in this study include the irradiation time, microwave power level, feed particle size and feed-solvent ratio.

\section{Dispersive X-ray Analysis (EDX)}

The elemental analysis was conducted using Hitachi plus Tabletop Microscope (TM 3030, USA). In this study, the elemental compositions of fresh dried black and white peppers were obtained through energy-dispersive X-ray (EDX) spectroscopy at 
magnification of $40-300 \mathrm{x}$ and voltage of $15 \mathrm{kV}$. The sample was coated with gold thin layer to decrease the electron charge on sample surface and enhance sharpness at $30 \mathrm{~s}$ acquisition time.

\subsection{RESULTS AND DISCUSSIONS}

\section{Effects of different parameters on the extraction yield}

Four extraction parameters were considered, viz. irradiation time $\left(\mathrm{m}_{1}\right)$, microwave power level $\left(\mathrm{m}_{2}\right)$, feed particle size $\left(\mathrm{m}_{3}\right)$ and feed-solvent ratio $\left(\mathrm{m}_{4}\right)$. The effects of these factors on extraction yield and absorbed energy were then discussed.

\section{Effect of Irradiation Time}

The effects of irradiation time on extract yield were studied by varying at 20, 40, 60, 80, and 100 mins. Microwave power, particle size and feed-solvent ratio were made constant at $200 \mathrm{~W}, 0.105 \mathrm{~mm}$ and 1:6, respectively. There was an increase in the oleoresin yield as time increased to a maximum value of 80 and 60 mins in black and white pepper refluxation, respectively. This is reflected in their energy absorption capacities, from which black pepper absorbed more of the microwave energy than white pepper. This indicated that the microwave energy required in breaking the elongated parenchymatous and stone-like cells in black pepper was more than that in white pepper (Olalere et al., 2017). Thus, maximum yield and absorbed energy were recorded at 80 and 60 min in black and white microwave reflux. Beyond these points, quantity of fixed oil extracted decreased with a corresponding decline in the absorbed energy as shown in Figure 1.

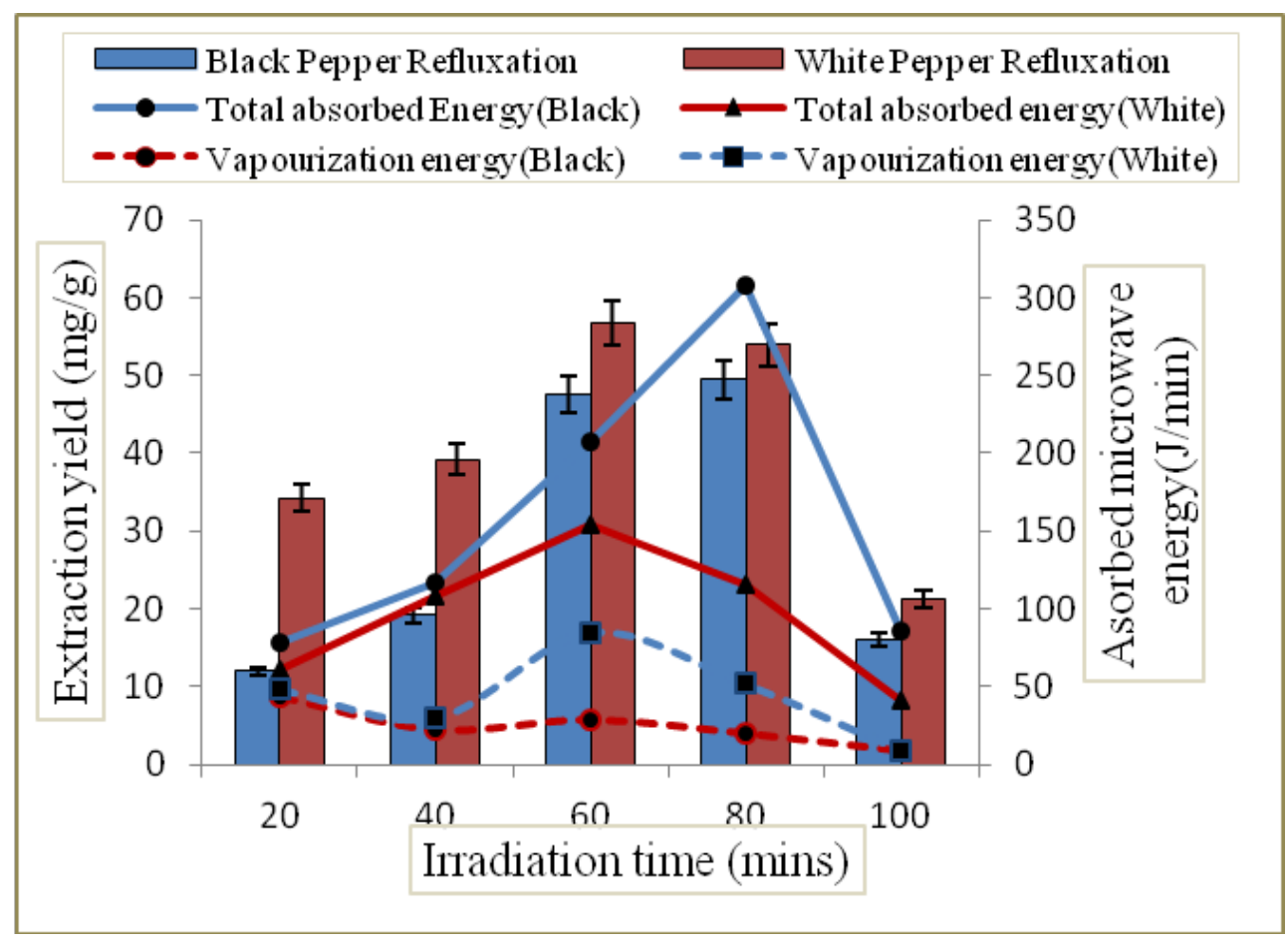

Figure 1: Effects of irradiation time

However, the differences in maximum irradiation time for the two pepper species could be attributed to differences in their structural configuration, occasioned by maturation time (Abdurahman and Olalere, 2016; Freire et al., 2000; Olalere et al., 2017). The energy absorbed by black pepper during the extraction process was more than the one absorbed 
by white pepper. The differences in the amount of energy absorbed by the two pepper sample could be attributed to the higher force of attraction at the cellulosic cell wall of the black pepper (Jagella and Grosch, 1999; Olalere et al., 2017).

\section{Effect of Microwave Power}

The effects of microwave power on the extraction yield and energy absorption was achieved by varying the power $(200,250,300,350,400 \mathrm{~W})$ at constant particle size $(0.105 \mathrm{~mm})$, feed-solvent ratio (1:6) and irradiation time (80 min for black pepper and 60 min for white pepper) as shown in Figure 2.

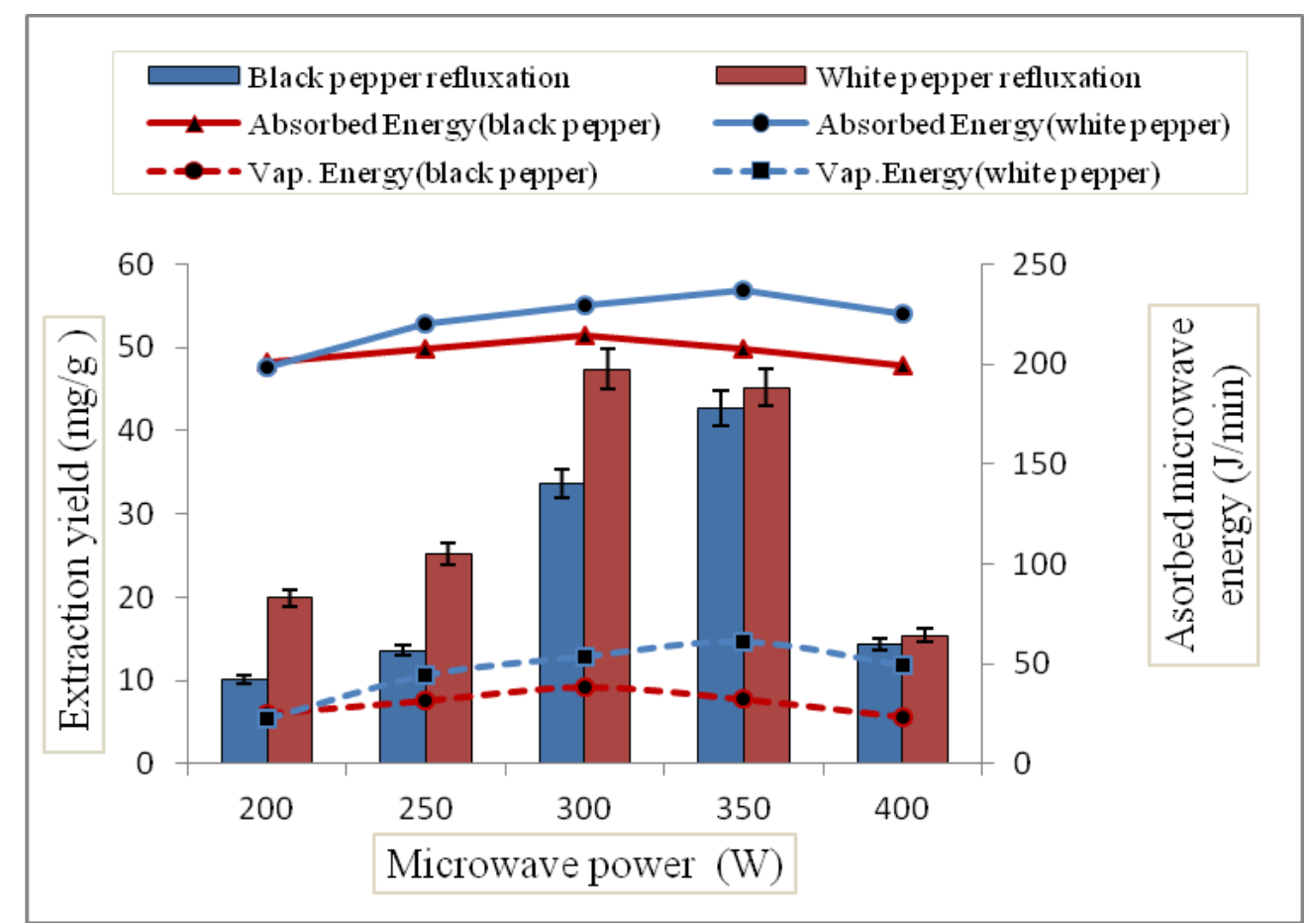

Figure 2: Effects of microwave power

The results showed a steady increase in the fixed oil extracted with microwave power ranging from 200 to $300 \mathrm{~W}$. The sudden rise is attributed to the opening-up of cellulosic cell wall, which triggered the release of more energy to water-pepper system. This produced an induction effect which accelerated the conduction of ions and dipole rotation resulting in ionic migration as reported by Khajeh and Ghanbari. (2011). However, the highest extraction yield was attained with microwave power of $300 \mathrm{~W}$ and $350 \mathrm{~W}$ in white and black pepper refluxation, respectively. At this point, the exudation of bioactive compound from both pepper matrixes were at their maximum points; beyond these points, a drastic reduction in extractable fixed oil was noticeable. Therefore, it can be clearly seen that there was a direct proportionality between the extraction yield and the energy absorbed by the water-sample system. This energy is a combination of sensible energy and energy required in vaporizing the extracting solvent (water).

\section{Effect of Particle Size}

The particle sizes were varied as $0.105 \mathrm{~mm}, 0.154 \mathrm{~mm}, 0.300 \mathrm{~mm}, 0.45 \mathrm{~mm}$ and 0.900 $\mathrm{mm}$ at constant feed-solvent ratio $(1: 6)$, microwave power $(350 \mathrm{~W}$ for black refluxation and $300 \mathrm{~W}$ for white refluxation), irradiation time ( $80 \mathrm{~min}$ for black refluxation and 60 min for white refluxation) as illustrated in Figure 3. 


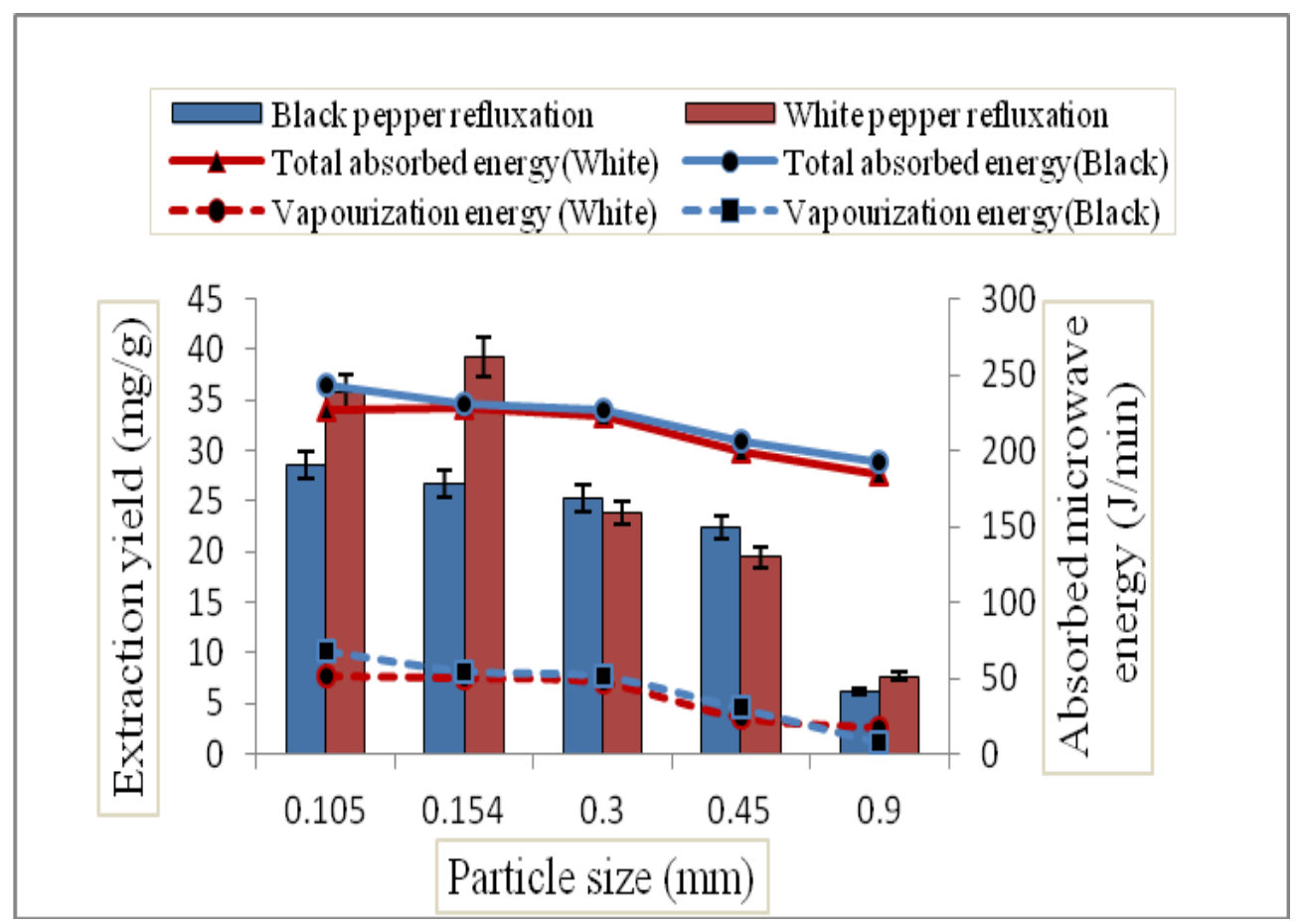

Figure 3: Effects of particle size

The maximum extraction yield was experienced with the particle size of $0.105 \mathrm{~mm}$ and $0.154 \mathrm{~mm}$ for black and white pepper reflux, respectively. This indicated that, a finely divided pepper as smaller as $0.105 \mathrm{~mm}$ is required to obtain maximized yield from black pepper (Huie, 2002). Smaller particle size presents larger surface area for solvent penetration, and hence an increase extraction yield. Chupin et al. (2015) also reported that, coarse sample provided a low dielectric heating and therefore requires higher microwave energy in breaking through their microstructure. On the contrary, there is exception to fine particles resulting in higher extraction yield. Tatke and Jaiswal (2011) reported that the use of smaller particle sizes can results in some of the bioactive component becoming trapped during the centrifugation and filtration, thereby reducing yield and efficiency.

\section{Effect of Feed-Solvent Ratio}

The feed-solvent ratio was varied as 1:6, 1:8, 1:10, 1:12 and 1:14 at constant microwave power ( $350 \mathrm{~W}$ for black pepper refluxation and $300 \mathrm{~W}$ for white pepper refluxation), irradiation time $(80 \mathrm{~min}$ for black pepper refluxation and $60 \mathrm{~min}$ for white pepper refluxation) and particle sizes $(0.105 \mathrm{~mm}$ for black pepper refluxation and $0.154 \mathrm{~mm}$ for white pepper refluxation) as shown in Figure 4. The results from this variation, showed an initial rise in extraction yield from 1:6 to 1:12 in black and white pepper refluxation,

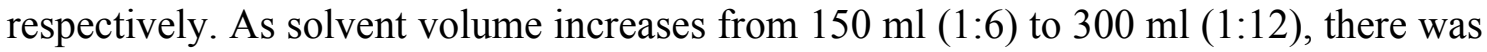
a responsive increase in the fixed oil extracted. Beyond this maximum point, the fixed oil extracted plummeted resulting in the reduction of energy dissipation (Mihaela and Simona, 2007). This suggests that with an increase in solvent volume, most of the microwave energy emitted goes into the vaporization of the large volume of water as reported by Desai and Parikh (2012). 


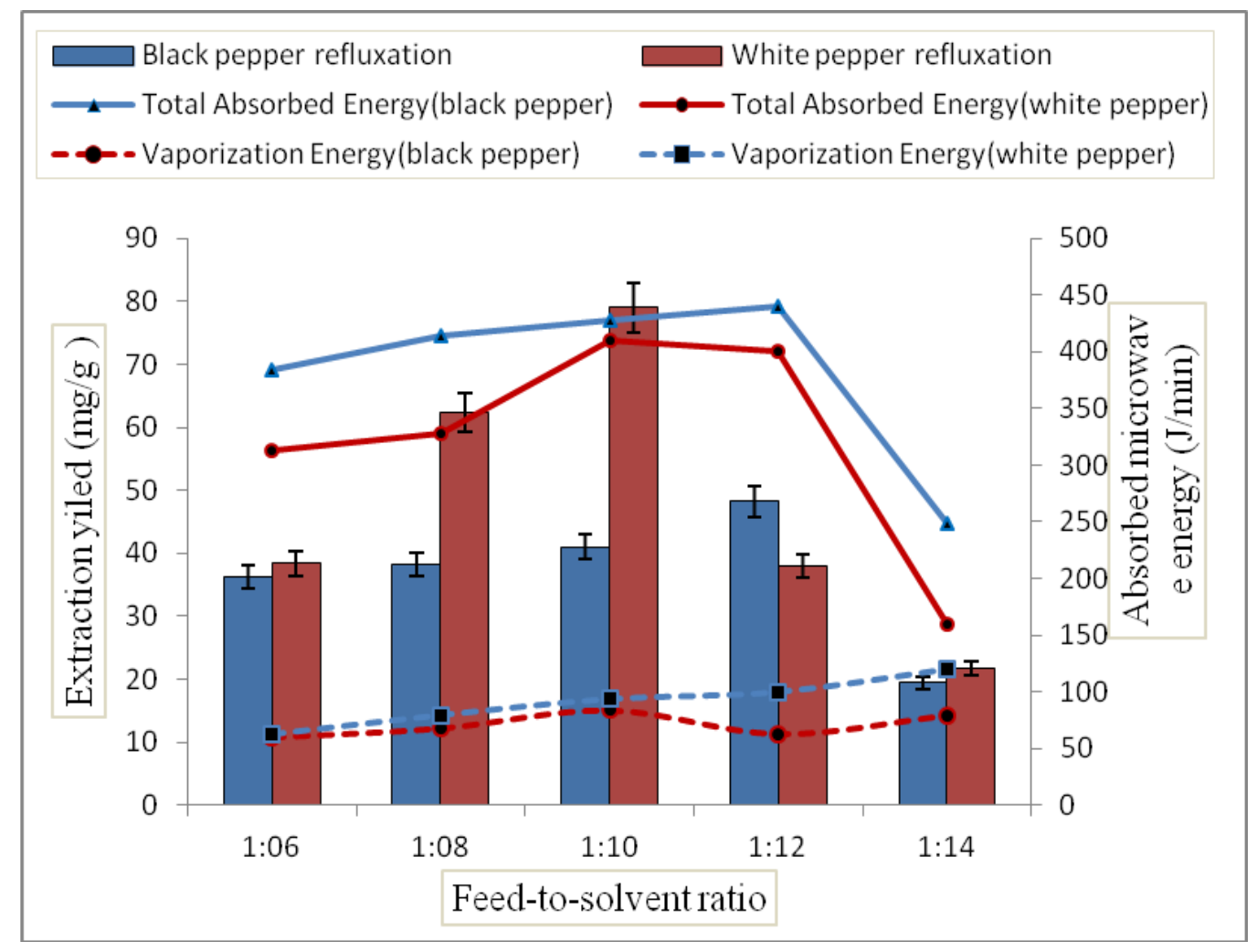

Figure 4: Effects of feed-solvent ratios

\section{Determination of Optimal Condition and Design Validation}

Best extraction conditions were obtained from the single factor experimental results. The choice of the best extraction condition was based on the 'largest donating rule' which states that, as far as each investigated factors is concerned, the largest value which affects the response should be the selected value (Liang et al., 2015). Table 1 shows the summary of the best extraction conditions for both black and white pepper microwave refluxation.

Table 1: Summary of selected extraction condition

\begin{tabular}{lllll}
\hline Parameters & Symbol & Unit & $\begin{array}{l}\text { Black pepper } \\
\text { refluxation }\end{array}$ & $\begin{array}{l}\text { White pepper } \\
\text { refluxation }\end{array}$ \\
\hline Extraction time & $\mathrm{m}_{1}$ & $\mathrm{~min}$ & 80 & 60 \\
Microwave power & $\mathrm{m}_{2}$ & $\mathrm{~W}$ & 350 & 300 \\
Particle size & $\mathrm{m}_{3}$ & $\mathrm{~mm}$ & 0.105 & 0.154 \\
Feed-solvent ratio & $\mathrm{m}_{4}$ & - & $1: 12$ & $1: 10$ \\
Extraction yield & - & $\mathrm{mg} / \mathrm{g}$ & 48.22 & 79.02 \\
Energy absorbed & - & $\mathrm{J} / \mathrm{min}$ & 439.58 & 409.21 \\
\hline
\end{tabular}

Triplicate confirmatory tests were conducted from the predicted optimal yield for black and white pepper refluxation. From the parallel tests for black pepper refluxation, an extraction yield of $48.16,48.23$ and $47.96 \mathrm{mg} / \mathrm{g}$ were obtained. Also, the triplicate confirmatory tests for the absorbed microwave energy were 439.55, 440.18, and 439.58 $\mathrm{J} / \mathrm{min}$. Moreover, in white pepper refluxation; the parallel tests conducted gave the extraction yield of $79.00,79.06$ and $79.09 \mathrm{mg} / \mathrm{g}$. In absorbed energy, the triplicate tests were 408.78, 409.22 and $409.21 \mathrm{~J} / \mathrm{min}$. On the overall, the X-goodness-of-fit values obtained indicated a no-significant difference between the predicted and actual optimum 
response settings. The $\mathrm{X}^{2}$-values were smaller when compared with the 7.81 cut-off value for a 3-degree of freedom at 95\% confidence level (Alara et al., 2017).

\section{Elemental Analysis}

From the elemental analysis conducted on both extracts, a total of 11 dietary elements were identified. These include; carbon, oxygen, magnesium, aluminium, silicon, phosphorous, calcium, phosphorus, potassium, nitrogen and sulphur. It is important to note that no harmful elements were detected in this study. The results revealed that the relative abundance of the dietary element in white pepper extract is much more than in black pepper. This could be attributed to the differences in the processing method as reported by Olalere et al. (2017). From the dietary elemental composition, carbon and oxygen have the highest concentration, while magnesium, aluminium, silicon, calcium, and potassium are in moderate amount as presented in Table 2.

Table 2: Elemental composition of extracts obtained

\begin{tabular}{lcccc}
\hline S/N & Element & Chemical symbol & $\begin{array}{c}\text { BPOE } \\
\text { weight }(\%)\end{array}$ & $\begin{array}{c}\text { WPOE } \\
\text { weight }(\%)\end{array}$ \\
\hline 1 & Carbon & $\mathrm{C}$ & 51.012 & 47.189 \\
2 & Oxygen & $\mathrm{O}$ & 36.202 & 37.430 \\
3 & Aluminium & $\mathrm{Al}$ & 2.606 & 3.001 \\
4 & Magnesium & $\mathrm{Mg}$ & 4.291 & 5.013 \\
5 & Silicon & $\mathrm{Si}$ & 1.942 & 2.450 \\
6 & Calcium & $\mathrm{Ca}$ & 1.203 & 1.704 \\
7 & Phosphorus & $\mathrm{P}$ & 0.200 & 0.246 \\
8 & Potassium & $\mathrm{K}$ & 2.072 & 2.270 \\
9 & Nitrogen & $\mathrm{N}$ & 0.150 & 0.183 \\
10 & Sulphur & $\mathrm{S}$ & 0.321 & 0.511 \\
11 & Chlorine & $\mathrm{Cl}$ & 0.001 & 0.003 \\
\hline
\end{tabular}

\subsection{CONCLUSION}

Many studies were conducted on the extraction of spice oleoresin from black and white pepper via microwave assisted extraction technique. This study investigated the effects of microwave electromagnetic heating on the extraction yield, energy and dietary elemental composition of spice oleoresin extracts from black and white pepper extracts. The extraction yield absorbed under the largest donating rule was much higher in white pepper extracts than the black pepper. However, the absorbed energy by the water-pepper sample in white pepper was lower when compared with the black pepper refluxation. This indicated a higher energy requirement in black pepper microwave extraction than white pepper, which could be attributed to the higher force of attraction holding their cellulose cell wall together. In a complex structured samples as black and white pepper, a trade-off has to be decided between either using a higher microwave power, lower irradiation time and vice versa.

\section{ACKNOWLEDGEMENT}

The author gratitude goes to the Research and Innovation Department, Universiti Malaysia Pahang, Malaysia, for their support through the PGRS160320 research grant and also to the Doctoral Scholarship Scheme (DSS) for their financial support. 


\section{REFERENCES}

Abd El-Mageed, M.A. (2011). The Effect of Microwaves on Essential oils of White and Black Pepper (Piper nigrum L.) and their Antioxidant Activities. Journal of Essential Oil Bearing Plants, 14(2), 214-223.

Abdurahman, N.H., Olalere, O.A. (2016). Taguchi-Based Based Optimization Technique in Reflux Microwave Extraction of Piperine from Black Pepper (Piper nigrum). Australian Journal of Basic and Applied Sciences, 10(10), 293-299.

Abdurahman, N.H., Olalere, O.A. (2016). A Comparative Review Of Conventional And Microwave Assisted Extraction In Capsaicin Isolation From Chili Pepper. Australian Journal of Basic and Applied Sciences, 10(6), 263-275.

Alara, O.R., Abdurahman, N.H., Olalere, O.A. (2017). Effect of drying methods on the free radicals scavenging activity of Vernonia amygdalina growing in Malaysia. Journal of King Saud University - Science.

Buckle, F. (1985). Compositional Differences of Black, Green and White Pepper (Piper nigrum L .) Oil From Three Cultivars. International Journal of Food Science \& Technology 20(5), 599 - 613

Chupin, L. (2015). Microwave Assisted Extraction of Maritime Pine (Pinus pinaster) bark: Impact of Particle Size and Characterization. Industrial Crops and Products, 65(1), 142-149.

Dargahi, M. (2012). High Temperature Synthesis of SAPO-34: Applying an L9 Taguchi Orthogonal Design to Investigate the Effects of Experimental Parameters. Powder Technology, 217,223-230.

Desai, M. A. \& Parikh, J. (2012). Microwave Assisted Extraction of Essential Oil From Cymbopogon Flexuosus (Steud.) Wats.: A Parametric and Comparative Study. Separation Science and Technology, 47(13), 1963-1970.

Freire, F., Kozakiewicz, Z. \& Paterson, R. (2000). Mycoflora and Mycotoxins in Brazilian Black Pepper, White Pepper and Brazil nuts. Mycopathologia, 149(1), 13-19.

Friedman, M. (2008). Analysis by HPLC and LC/MS of Pungent Piperamides in Commercial Black, White, Green, and Red Whole and Ground Peppercorns. Journal of Agricultural and Food Chemistry, 56(9), 3028-3036.

Huie, C.W. (2002). A Review Of Modern Sample-Preparation Techniques for the Extraction and Analysis of Medicinal Plants. Analytical and Bioanalytical Chemistry, 373(1-2), 23-30.

Jagella, T. \& Grosch, W. (1999). Flavour and Off-flavour Compounds of Black and White Pepper (Piper nigrum L.). Evaluation of Potent Odorants of Black Pepper By Dilution and Concentration Techniques. European Food Research and Technology, 209(1), 16-21.

Jyothi, D., Khanam, S. \& Sultana, R. (2010). Optimization of Microwave Assisted Extraction of Withanolides from Roots of Aswagandha and Its Comparison with Conventional Extraction Method. International Journal of Pharmacy and Pharmaceutical Science, 2(4), 46-50.

Khajeh, M. \& Ghanbari, A. (2011). Application of Factorial Design and Box-Behnken Matrix in the Optimisation of a Microwave-assisted Extraction of Essential Oils from Salvia Mirzayanii. Natural Product Research, 25(18), 1766-70.

Liang, C. (2015). Novel synthesis of 8-mercaptomethone via pulegon and disodium tetrasulphide ignited by Dowex ® 50WX4. Journal of Chemical and Pharmaceutical Research, 7(4), 278-281.

Madhu, M.N., Ramalingam, R. \& Swetha, D. (2009). Extraction, Identification, Formulation and Evaluation of Piperine in Alginate Beads. International Journal of Pharmacy and Pharmaceutical Sciences, $1(2), 156-161$.

Meghwal, M. \& Tk, G. (2012). Nutritional Constituent of Black Pepper as Medicinal Molecules :A Review. Open Access Scientific Reports, 1(1), 1-7.

Mehmood, M.H. \& Gilani, A.H., 2010. Pharmacological Basis for the Medicinal Use of Black Pepper and Piperine in Gastrointestinal Disorders. Journal of Medicinal Food, 13(5), pp.1086-96.

Mihaela, N.S. \& Simona, N.(2007). Microwave-Assisted Extraction ( MAE) of Secoisolariciresinol Diglucoside ( $S D G$ ) from Flaxseed.

Moraes, N.M. (2013). Obtaining Antioxidants from Botanic Matrices Applying Novel Extraction Techniques. Food and Public Health, 3(4), 195-214.

Olalere, O.A. Abdurahman, N.H., Alara, O.R. \& Habeeb, O.A. (2017). Parametric Optimization of Microwave Reflux Extraction of Spice Oleoresin from White Pepper (Piper nigrum). Journal of Analytical Science and Technology, 8(1), 8.

Olalere, O.A., Abdurahman, N.H. \& Alara, O.R., 2017. Extraction, radical scavenging activities and physicochemical fingerprints of black pepper (Piper nigrum) extract. Journal of Food Measurement and Characterization.

Qu, X. \& Wu, C.F.J., (2005). One-factor-at-a-time Designs of Resolution V. Journal of Statistical Planning and Inference, 131(2), 407-416.

Raman, G. \& Gaikar, V. (2002). Microwave-assisted Extraction of Piperine from Piper nigrum. Industrial 
\& Engineering Chemistry Research, 41, 2521-2528.

Singh, S. (2013). Chemistry, Antioxidant and Antimicrobial Potentials of White pepper (Piper nigrum L.) Essential Oil and Oleoresins. Proceedings of the National Academy of Sciences India Section B Biological Sciences, 83(3), 357-366. 